\title{
The DNA Triangle and Its Application to Learning Meiosis
}

\author{
L. Kate Wright, ${ }^{+*}$ Christina M. Catavero, ${ }^{*}$ and Dina L. Newman ${ }^{\dagger}$ \\ Thomas H. Gosnell School of Life Sciences, Rochester Institute of Technology, \\ Rochester, NY 14623
}

\begin{abstract}
Although instruction on meiosis is repeated many times during the undergraduate curriculum, many students show poor comprehension even as upper-level biology majors. We propose that the difficulty lies in the complexity of understanding DNA, which we explain through a new model, the DNA triangle. The DNA triangle integrates three distinct scales at which one can think about DNA: chromosomal, molecular, and informational. Through analysis of interview and survey data from biology faculty and students through the lens of the DNA triangle, we illustrate important differences in how novices and experts are able to explain the concepts of ploidy, homology, and mechanism of homologous pairing. Similarly, analysis of passages from 16 different biology textbooks shows a large divide between introductory and advanced material, with introductory books omitting explanations of meiosis-linked concepts at the molecular level of DNA. Finally, backed by textbook findings and feedback from biology experts, we show that the DNA triangle can be applied to teaching and learning meiosis. By applying the DNA triangle to topics on meiosis we present a new framework for educators and researchers that ties concepts of ploidy, homology, and mechanism of homologous pairing to knowledge about DNA on the chromosomal, molecular, and informational levels.
\end{abstract}

\section{INTRODUCTION}

Meiosis, the cell division that creates mature sperm and ova in animals, is a process that relates to information flow, exchange, and storage-major ideas that have been identified as a core concept for biological literacy in undergraduate biology education (American Association for the Advancement of Science, 2011). Typically instruction on meiosis is repeated many times during the K-16 biology curriculum, because it is extremely important in the contexts of genetics, information flow, and evolution, but many students show poor comprehension even as upper-level biology majors (Dikmenli, 2010; Smith and Knight, 2012). The molecular mechanisms and genetic outcomes of meiosis are embedded in a large number of topics that will likely be encountered by the typical biology student during his/her undergraduate education. Some of these topics are linked with the molecular mechanisms that drive meiosis, such as DNA repair by homologous recombination, mechanisms of genetic inheritance, development of chromosomal aberrations (e.g., trisomy), and the phenomenon of chromosomal translocations in human cancer. Hence, surface-level knowledge of or misunderstanding the process of meiosis, and how it really works, may interfere with deeper learning of related topics as a student progresses through his/her undergraduate biology curriculum.

The biology education literature shows that students have particular difficulties with concepts related to the process of meiosis (Johnstone and Mahmoud, 1980; Stewart et al., 1990; Kindfield, 1991, 1994; Marbach-Ad, 2001; Dikmenli, 2010; Wright and Newman, 2011; Newman et al., 2012; Kalas et al., 2013). Topics related to chromosomes and meiosis are first encountered in high school or even middle school science classes, so many students may actually feel a false sense of mastery of these

Joel K. Abraham, Monitoring Editor Submitted March 9, 2017; Revised June 5, 2017 Accepted June 8, 2017

CBE Life Sci Educ September 1, 2017 16:ar50 DOI:10.1187/cbe.17-03-0046

'These authors contributed equally to the work. FPresent address: Department of Neuroscience, University of North Carolina, Chapel Hill, NC 27599

*Address correspondence to: L. Kate Wright (lkwsbi@rit.edu).

(c) 2017 L. K. Wright et al. CBE-Life Sciences Education (๑) 2017 The American Society for Cell Biology. This article is distributed by The American Society for Cell Biology under license from the author(s). It is available to the public under an Attribution-Noncommercial-Share Alike 3.0 Unported Creative Commons License (http:// creativecommons.org/licenses/by-nc-sa/3.0). "ASCBß" and "The American Society for Cell Biology ${ }^{\circledR}$ " are registered trademarks of The American Society for Cell Biology. 
topics when they are presented again in the undergraduate curriculum. However, research demonstrates that meiosis and related topics are very challenging for most secondary students to learn in the first place (Shaw et al., 2008; Freidenreich et al., 2011; Kilic et al., 2016). Concepts about inheritance and the nature of genes and alleles are challenging for any learner, especially younger students. It is no wonder that many postsecondary students continue to struggle with complex processes of meiosis, cell division, and genetics, as has been well documented by the biology education research community.

We have been investigating student understanding of meiosis at the postsecondary level for several years. Our large data set, which includes class artifacts, assessment responses, survey data, and interview transcripts, has allowed us to take a holistic view and focus on fundamental differences between how students and experts are able to comprehend the process of meiosis. Disciplinary experts not only have a deep content knowledge but are able to adapt, organize, connect, and apply knowledge in a dynamic and meaningful way (Newell and Simon, 1972; Bédard and Chi, 1992; Chi, 2006). In this study, we present evidence that faculty (experts) are able to connect and use knowledge about DNA at the chromosomal, molecular, and informational levels to explain complex ideas such as ploidy, homology, and the mechanism of homologous pairing that drive chromosome behavior during meiosis. Students (novices), on the other hand, have superficial and fragmented knowledge about these same ideas and have difficulty connecting ideas to explain mechanisms or outcomes of meiosis.

Johnstone's triangle is a framework developed by chemistry education researchers to explain the difficulties novice chemistry students have moving between levels of representation in chemistry (Johnstone, 1991, 2000). Johnstone postulated that chemistry understanding encompasses three levels: macroscopic, submicroscopic, and symbolic. Experts can move between all three levels with ease and understand the relatedness of, for example, salt crystals (macroscopic level), the chemical structure for salt (submicroscopic or molecular level), and a symbolic representation such as a chemical formula or equation (symbolic level). Novices, meanwhile, have trouble understanding how the levels relate to one another and cannot visualize the same entity at different scales (Kozma and Russell, 1997).

Similar to chemistry students' inability to transfer knowledge from one level to another, in previous work we demonstrated that students do not transfer their content knowledge about DNA when working with different levels of representations in the context of meiosis (Newman et al., 2012). In other words, students do have knowledge of DNA structure at the molecular level, but do not use it when presented with phenomena that must be explained by molecular-level interactions involving DNA. When asked to draw, model, and/or describe meiosis, students often focus on the chromosomal scale-what is visible at the beginning and end of the process. While many students know what the beginning and end products of meiosis should look like, they have multiple flaws in their models of the whole process (Kindfield, 1994; Wright and Newman, 2011; Newman et al., 2012), because they do not consider the molecular structure and behavior of DNA (DNA replication, complementary base-pairing during crossing over, etc.) that drives chromosome behavior and the outcomes on an informational scale (e.g., to articulate allele segregation, results of crossovers and recognition of sets of genetic information; Newman et al., 2012).

In this paper we used a grounded approach for a first-pass analysis to examine student, faculty, and textbook presentations of meiosis to develop a new framework (the DNA triangle) to explain the difference between expert and novice mental models. Once this model was developed, we took a deductive approach for a second-pass analysis of old and new data through the lens of the new framework. We propose that the DNA triangle is a generalizable model that can be used for the teaching and learning of meiosis as well as other processes involving DNA.

\section{METHODS \\ Overview}

We followed a grounded approach, illustrated by the outline in Figure 1. A first-pass analysis of student interview data, assessment data, expert statements, and textbook passages helped us develop our theory and framework following a grounded approach. Grounded theory methodology was developed by Glaser and Strauss (1967), and further articulated by others (e.g., Martin and Turner, 1986; Strauss and Corbin, 1997; Komives et al., 2006; Levrini et al., 2015) as an answer to the trend of positivism that dominated much of social science research. In other words, research methods and theories should not be selected to simply support a pre-existing idea about what a data set holds; rather, findings and new theories should emerge from data in an organic way. This is not to say that existing theories and prior research findings have no bearing on grounded theory methodology; they most certainly do. Suddaby (2006, p. 634) describes the grounded theory approach as "an organic process of theory emergence based on how well data fit conceptual categories identified by an observer, by how well the categories explain or predict ongoing interpretations, and by how relevant the categories are to the core issues being observed." In other words, literature and existing theories help inform current research questions and frame the data-collection process, but the researcher does not make assumptions about what the data may hold. Once themes and categories emerge from the data, the researcher is able to test those categories against other data sets and map the findings back against the original research question. We did this in a second-pass analysis of our data.

The methodology we used allowed us to develop a new theory grounded in a large collection of data about how people conceptualize the process of meiosis. This approach of looking for emergent themes in the data to develop a new framework that is then applied back to the data set is not uncommon in the discipline-based education research literature (e.g., Scherr, 2007; Powietrzynska et al., 2014; Galloway and Bretz, 2015).

\section{Student Population}

All student data presented were gathered with institutional review board approval. Student data were generated mainly by first- and second-year biology students in several different courses at a large private institution in the northeastern United States. Most students at this institution follow a fairly traditional curriculum: a first-year introductory biology course, followed by cell and molecular biology and then genetics. Students are introduced to meiosis in the Fall semester of the 


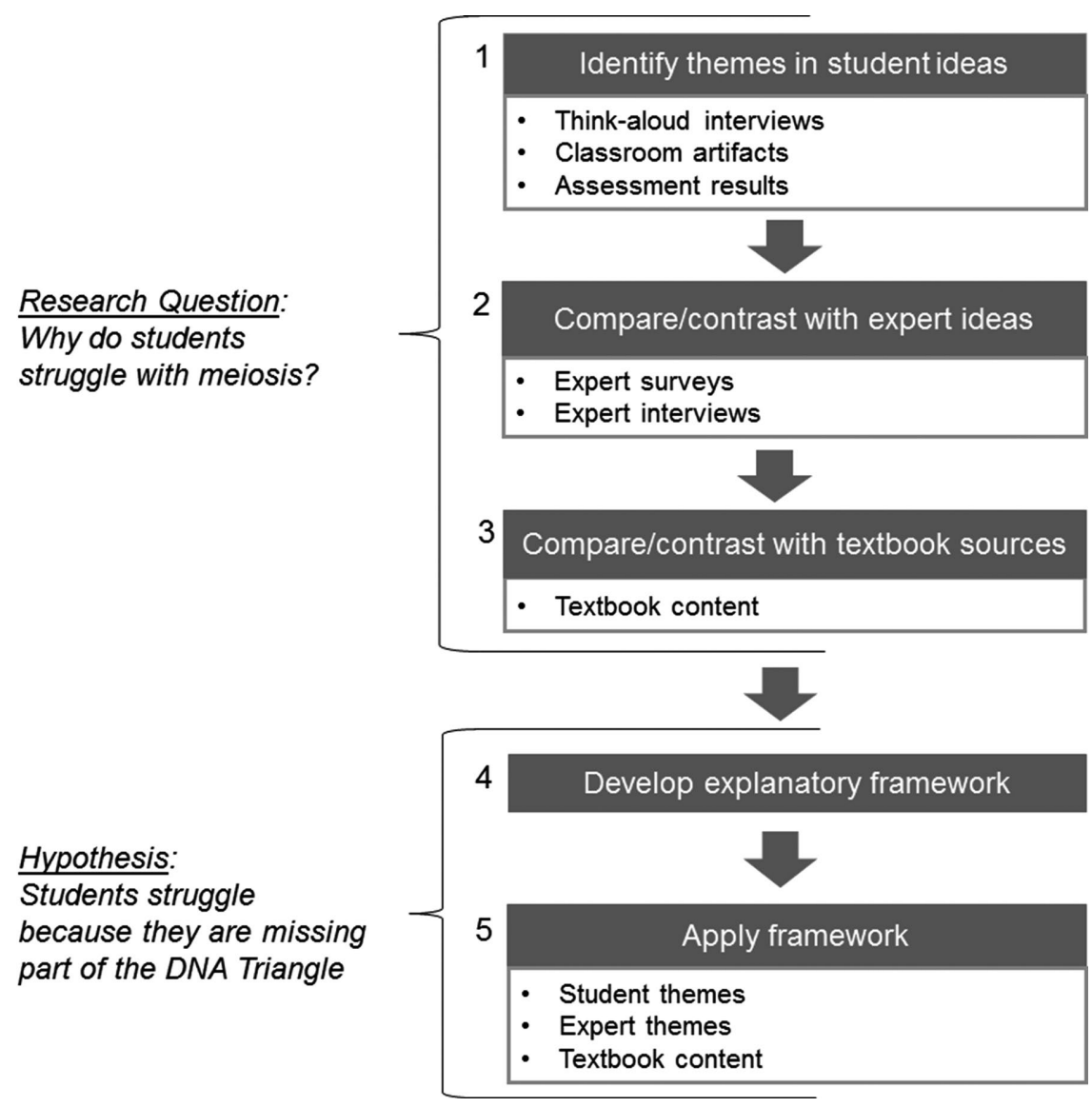

FIGURE 1. Outline of methodology. To investigate the question of why students struggle with meiosis, we took a grounded approach (steps 1-3), which led to the development of a new framework (step 4) and refinement of the research question to a specific hypothesis. In the final step (5), we applied the framework to our data to test our hypothesis. a diagram of a precursor germ cell containing six unreplicated chromosomes followed by a series of empty cells at different stages of meiosis I and II. Participants were given time (10-15 minutes) to think about and draw in the chromosomes as they would appear at different times during the process of meiosis and to note whether cells were diploid or haploid during each major step of the process. Participants were then asked to explain to the interviewer what was happening at each step and were asked follow-up questions to clarify their answers. They were then asked to explain their understanding of homologous chromosomes and crossing over in relation to the process of meiosis. In protocol 2, participants were asked to read through and answer each question from the meiosis assessment (see below; $N=10$ interviews conducted with 10 students). Participants were asked to explain the reasoning behind each of the responses they gave to the interviewer.

Online Survey 1 to Establish What Is We have been thinking about student difficulties with meiosis for a long time. Through our own work (Wright and Newman, 2011; Newman et al., 2012) and work from the biology education research community (e.g., Kindfield, 1991, 1994; Kalas et al., 2013), we had collected a lot of interesting ideas on why this topic was so difficult for biology learners. Through freshman year, and the topic is revisited in both cell and molecular biology and genetics.

\section{Step 1: Identify Themes from Student Ideas}

The overarching research question explored in this study was "Why do students struggle with meiosis?" To tackle this question, we analyzed data from a variety of sources, including survey responses, open-ended assessments, classroom observations, and interviews with students. We used inductive strategies (Johnson and Christensen, 2008) to analyze student responses to questions on a meiosis assessment and in interview transcripts from semistructured interviews with students about their understanding of meiosis. Inductive strategies can be a useful way to identify themes and patterns from a large collection of qualitative data (Otero and Harlow, 2009). Thus, we were able to use thematic analysis to describe typical student reasoning about concepts related to the process of meiosis.

Interviews with Biology Students. A total of 27 interviews were conducted with students in biology or biology-related programs. Interviews were semistructured and followed one of two main protocols. In protocol 1 , interviews were conducted with pairs or single students ( $N=17$ interviews conducted with 24 total students). Subjects were given a worksheet containing informal discussions with colleagues and faculty at outside institutions, we realized the difficulties we encountered after $10+$ years of teaching biology were very similar to what other faculty had experienced. Informed by our own knowledge of meiosis and the issues students routinely exhibited, we developed a list of concept statements we believed were essential for understanding the process of meiosis because they would help a learner make further connections about the process (e.g., "chromosomes not chromatids determine ploidy" and "a cell becomes haploid after meiosis I"). To validate the importance of vey that contained our list of essential concept statements plus several superficial knowledge-level statements that would not promote a deep understanding of the process (e.g., "normal human gametes have 23 chromosomes" or knowledge of the names and phases of cell division). When this survey was created, it was not for the intention of creating a framework, it was to help us (as researchers) articulate what was most important for understanding the process of meiosis. We distributed the survey by email to biology faculty at 4-year liberal arts colleges and universities. We worked under the assumption that faculty at non-R1 institutions would be more consistently involved in teaching semester-long courses and have closer interactions with undergraduates compared with faculty at R1 institutions, what we considered to be the core concepts, we created a sur- 


\begin{tabular}{|c|c|c|}
\hline Larger concept & Statement & $\begin{array}{l}\text { Experts }(N=68) \text { who considered } \\
\text { the concept to be "core" or "very } \\
\text { important" }\end{array}$ \\
\hline \multirow[t]{2}{*}{ Mechanism of homologous pairing } & Physical linkage is essential for proper chromosome separation. & $75.0 \%$ \\
\hline & DNA sequence homology determines pairing. & $77.9 \%$ \\
\hline \multirow[t]{2}{*}{ Homology } & $\begin{array}{l}\text { Maternal and paternal chromosomes of the same kind are } \\
\text { homologous. }\end{array}$ & $100.0 \%$ \\
\hline & Homologous chromosomes are different than sister chromatids. & $98.5 \%$ \\
\hline \multirow[t]{4}{*}{ Ploidy } & Gametes are haploid. & $94.1 \%$ \\
\hline & Chromosomes rather than chromatids determine ploidy. & $80.9 \%$ \\
\hline & A cell becomes haploid after meiosis I. & $94.1 \%$ \\
\hline & $\begin{array}{l}\text { Chromosomes may contain one or two chromatids, depending } \\
\text { on whether or not DNA replication has taken place. }\end{array}$ & $92.6 \%$ \\
\hline
\end{tabular}

who might teach only part of a course and/or sporadically. We acknowledge that experiences of faculty may differ based on the type of institution and realize our feedback may be overly representative of faculty teaching top students at elite institutions. Regardless of these potential biases, we looked up the "top 100 liberal arts colleges" and searched biology department pages for faculty who taught courses such as introductory biology (majors and nonmajors level), molecular biology, cell biology, or genetics. We sent the online survey to 490 individuals and received complete responses from 68 (14\%). Participants were asked "How central do you consider each of these concepts to one's ability to understand the process of meiosis?" and responded to each of the concept statements using a four-point Likert scale ( 1 = core concept, 2 = important to know, 3 = worth being familiar with, and 4 = peripheral to understanding meiosis). We also asked participants to list any concepts we might have missed that they felt were essential to understanding meiosis, but none were suggested by the respondents. The concepts the majority of experts rated as being core/important are listed in Table 1. Results from this survey were used to construct a concept test that was used with undergraduate students to gauge their understanding of topics important to meiosis.

Development and Analysis of a Meiosis Assessment. To assess students' knowledge of concepts essential to understanding the process of meiosis, we designed a meiosis assessment (Supplemental Material) based on topics deemed important for understanding meiosis according to feedback from biology experts and our previous research experience investigating student knowledge about meiosis (Newman et al., 2012). The test used a short-answer format with 12 questions designed to probe students' ability to identify and explain ploidy, homology, and mechanism of homologous pairing in the context of the process of meiosis. Note that we are not arguing that these three concepts are the only concepts essential for meiosis understanding, but we chose to focus our efforts on these three areas.

Before the assessment was administered to students in a classroom setting, we recruited 10 undergraduate biology/ biotechnology/biomedical sciences majors for interviews to help us revise and clarify questions. Research participants answered the assessment questions while being videotaped in the presence of a researcher and were encouraged to think out loud and ask questions while taking the test. The interviews were transcribed and analyzed for 1) any misunderstanding of assessment test questions due to wording problems and 2) reasoning and knowledge about meiosis. The assessment was revised as necessary for clarity and was then administered to 69 students in a sophomore-level cell biology course before formal instruction on these topics. Students enrolled in the cell biology course entered with a year of freshman biology as a prerequisite. A rubric for the meiosis assessment questions was developed with the research team to score each question as correct or incorrect. Once all the responses were analyzed for correctness, we reanalyzed the responses to identify themes within the incorrect responses and to determine what was missing from incorrect answers. As with any written response, we cannot determine what a student truly "knows"-we can infer it only from the reasoning provide in the written answer. This inductive approach allowed us to articulate what reasoning would be needed to correctly answer each question. See Table 2 for a description of assessment questions and explanations of correct reasoning.

\section{Step 2: Compare/Contrast Student and Expert Ideas}

The literature and our preliminary survey results supported our findings that students struggled to explain the important meiosis-related concepts of homology, ploidy, and mechanism of homologous pairing. We reasoned that, because biology experts are able to correctly explain important meiosis-related concepts, comparing explanations provided by students (novices) with those provided by experts would help us identify "gaps" in student reasoning. Thus, the novice-expert continuum framework is useful when trying to articulate how novices compare with experts in conceptualizing a particular concept or process (e.g., Kindfield, 1994; Hmelo-Silver et al., 2007).

Interviews with Biology Experts. Analysis of interview transcripts with biology students allowed us to identify themes in how students reasoned about concepts related to meiosis. To reveal expert thinking, we asked experts to explain meiosis as though the interviewer had little knowledge about the subject. We thought that this strategy would help the interviewee stay 
TABLE 2. Student responses to questions from meiosis assessment

\begin{tabular}{|c|c|c|c|}
\hline Questions & $\begin{array}{l}\text { Students who } \\
\text { answered correctly } \\
(N=69)\end{array}$ & $\begin{array}{l}\text { To answer the question } \\
\text { completely (and correctly), } \\
\text { students must be able to: }\end{array}$ & Typical features of wrong answers \\
\hline $\begin{array}{l}\text { Q1. The figure at right represents a } \\
\text { diploid precursor germ cell [chromo- } \\
\text { somes are unreplicated]. How many } \\
\text { chromosomes are shown and what is } \\
\text { the value of "N"? }\end{array}$ & $26.1 \%$ & \multirow[t]{2}{*}{$\begin{array}{l}\text { Link chromosomal and informa- } \\
\text { tional aspects of DNA to } \\
\text { correctly identify ploidy of } \\
\text { cells before and after DNA } \\
\text { replication. }\end{array}$} & \multirow{2}{*}{$\begin{array}{l}\text { Students often rely on chromosome } \\
\text { appearance rather than informa- } \\
\text { tional content in determining } \\
\text { ploidy. Thus, they assume cells that } \\
\text { contain two-DNA (replicated) } \\
\text { chromosomes are diploid and cells } \\
\text { that contain one-DNA (unrepli- } \\
\text { cated) chromosomes are haploid. }\end{array}$} \\
\hline $\begin{array}{l}\text { Q3. Circle all haploid cells in the figure of } \\
\text { meiosis below. [Figure shows a } \\
\text { diploid cell before and after meiosis I } \\
\text { and meiosis II] }\end{array}$ & $4.3 \%$ & & \\
\hline $\begin{array}{l}\text { Q6. How do homologous chromosomes } \\
\text { find each other to pair properly? }\end{array}$ & $4.35 \%$ & \multirow{4}{*}{$\begin{array}{l}\text { Link molecular and chromosomal } \\
\text { concepts to correctly explain } \\
\text { the underlying mechanism of } \\
\text { homologous pairing and } \\
\text { explain its importance to } \\
\text { segregation in terms of } \\
\text { information content. }\end{array}$} & \multirow{4}{*}{$\begin{array}{l}\text { Students rarely consider the underly- } \\
\text { ing molecular mechanism and } \\
\text { rarely acknowledge that DNA } \\
\text { sequence (near) identity drives } \\
\text { homologous pairing. }\end{array}$} \\
\hline $\begin{array}{l}\text { Q7. What determines where crossing } \\
\text { over occurs? }\end{array}$ & $1.45 \%$ & & \\
\hline $\begin{array}{l}\text { Q9. Is crossing over necessary for } \\
\text { meiosis? Explain. }\end{array}$ & $0 \%$ & & \\
\hline $\begin{array}{l}\text { Q11. How similar are } \mathrm{X} \text { and } \mathrm{Y} \text { chromo- } \\
\text { somes? Why is this important? }\end{array}$ & $1.45 \%$ & & \\
\hline
\end{tabular}

focused on what he/she thought was truly important to know about the process. Six faculty members were recruited from five different universities for interviews. All of these experts had recent experience teaching meiosis to undergraduates. Interview participants were told they could use drawings or figures if they wished. Interview subjects were also probed for their thoughts about student difficulties associated with learning meiosis and were asked about specific areas they felt students had struggles with. If the concepts of ploidy, homology, or molecular mechanism of homologous pairing were not brought up by the expert during the interview, the interviewer asked for further explanations about those topics. Interviews lasted approximately 30-45 minutes and were conducted by videoconference or phone. Interviews were video- or audiotaped, and transcripts were made from each interview. Interview transcripts were analyzed by the research team to better understand how experts thought about meiosis, particularly examining how their responses differed from those of typical students. Themes that emerged from interviews with biology experts were used to design an online survey to gather additional information from experts.

Online Survey 2 with Biology Experts about the Concepts of Homology, Ploidy, and Homologous Pairing. To gather more information on how biology experts (academic faculty with a $\mathrm{PhD}$ in biology or a related field) thought about important concepts related to meiosis, we created a short online survey (using
Qualtrics) composed of three open-ended questions. Participants were asked to answer each of the following questions in one to two sentences: What determines whether two particular chromosomes will pair during meiosis? What makes two chromosomes homologous? What does ploidy (e.g., haploid, diploid) mean? The survey was distributed through an email listserv composed of members of the Society for the Advancement of Biology Education Research (SABER). A total of 50 individuals completed the survey. We used an emergent coding strategy to find themes within the survey responses.

\section{Step 3: Compare Findings with Textbook Sources} Analysis of Biology Textbooks for Meiosis-Related Concepts. We reasoned that important concepts related to meiosis should appear in various introductory and middle/upper-level biology textbooks. Therefore, we searched textbooks for the presence of the 10 concept statements found in Table 1 . We obtained six introductory and eight middle/upper-level biology textbooks from a range of publishers (Supplemental Table 1). PDF files of textbook chapters that discussed meiosis were provided by several publishers and imported into NVivo10 (QSR International). For the remaining textbooks, physical copies were obtained, and the relevant chapters were scanned and saved as PDF files, edited with Adobe Acrobat to enable text recognition, and then imported into NVivo10. Textbooks were examined by a researcher who extracted sentences relevant to meiosis from each textbook. All descriptive text within each chapter was 
analyzed, but figures and figure legends were not. C.M.C. and another researcher independently sorted the statements into the concepts categories using the criteria in Table 1 . Some passages did not meet the criteria for any category, while others met the criteria for multiple categories. Each mismatch between coders was debated until agreement was reached on the final coding. A heat map was generated from these data, compiling which concept statements were included in each book.

\section{Step 4: Develop Explanatory Framework}

Through consideration of all the themes we had documented, we developed a new framework to explain the difference between novice and expert thinking. One observation seemed particularly significant: experts recognize the importance of the base sequence of DNA, while most students do not talk about it at all in the context of meiosis. In addition, experts seemed to be able to integrate multiple representations of DNA in their minds, while students only spoke of one aspect at a time. These findings reminded us of Johnstone's triangle of chemistry representations, which we used as a basis for the development of our new framework, the DNA triangle, described in Figure 2A. The three corners of Johnstone's triangle (macroscopic, submicroscopic, symbolic) are analogous to three different scales of DNA: chromosomal (DNA as a key component of the structure of chromosomes that can be observed under the microscope), molecular (the underlying sequence of the nucleotide bases in a particular region of DNA, which is not directly observable), and informational (the abstract quality of DNA as genetic information). All of these facets must be integrated to achieve full
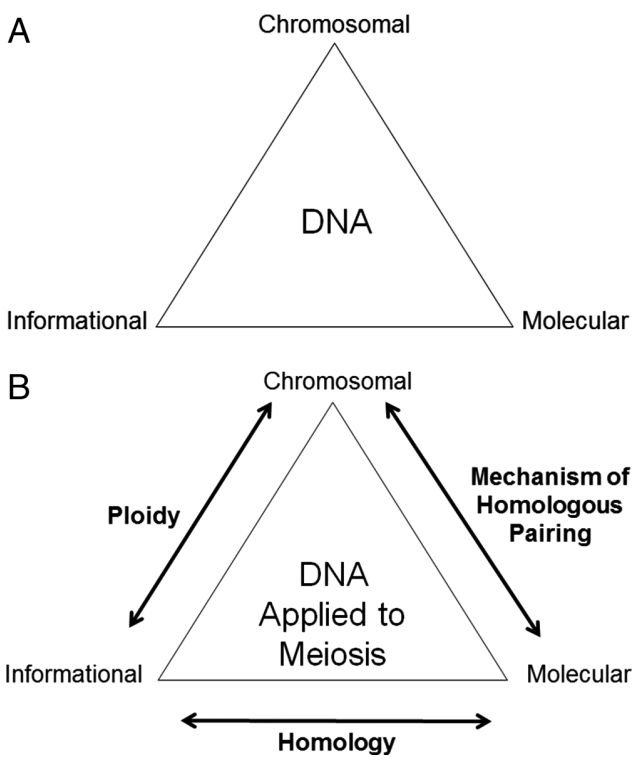

FIGURE 2. The DNA triangle. (A) Generalized model: thinking about DNA incorporates three different conceptual levels, all of which are linked: chromosomal, molecular, and informational. (B) DNA in the context of meiosis: understanding of the concept of ploidy relies on using information about DNA at the chromosomal and informational levels, the concept of homology relies on DNA knowledge at the informational and molecular levels, while the mechanism of homologous pairing relies on knowledge of DNA at the chromosomal and molecular levels. understanding of a complex process like meiosis. In particular, each of the three concepts we had been investigating (ploidy, homology, mechanism of homologous pairing) integrates two corners of the triangle (Figure 2B). This realization allowed us to develop a hypothesis in response to our broad research question investigating why students struggle to understand meiosis. We hypothesized that students struggle with meiosis because they are missing part of the DNA triangle.

\section{Step 5: Apply the Framework}

Once a model for student reasoning and understanding was developed, we were able to test our hypothesis by applying our DNA triangle framework to the data. This strategy was a deductive approach that required a second-pass analysis of transcripts from semistructured interviews with novices and experts, expert feedback on survey questions, and textbook passages about meiosis concepts. Deductive approaches allow the researcher to apply codes, criteria, or assumptions to a new data set (Otero and Harlow, 2009) in order to strengthen (or weaken) the proposed model. Thus, we were able to categorize themes and examples pulled from our collection of data from students and experts and code them using the DNA triangle (chromosomal, molecular, informational). We also coded passages about meiosis-related concepts from a new set of textbooks based on how information about DNA was integrated and presented to the reader.

Application of DNA Triangle Codes to Previous Data. Using the codes "chromosomal," "molecular," and "informational," we reanalyzed interview data (from students and experts) and the written responses experts provided to the questions in online survey 2: What determines whether two particular chromosomes will pair during meiosis? What makes two chromosomes homologous? What does ploidy (e.g., haploid, diploid) mean? Two researchers worked together to code the previously identified themes from interview data and expert-generated responses. Because written responses by experts often contained multiple ideas, each idea was coded separately.

Analysis of Textbooks. To investigate how concepts of ploidy, homology, and mechanism of homologous pairing were typically presented to biology students, we analyzed explanations of these concepts from seven introductory-level and nine middle/upperlevel college biology textbooks (Supplemental Table 2). Some of the textbooks were the same or newer editions of those used in the original textbook analysis, while others were new. We hypothesized that students' struggles with the molecular level of DNA knowledge may be partly due to how information about meiosis is presented to students. We used the index and the table of contents to find sections of the text that provided explicit descriptions about homology/homologous chromosomes, ploidy, and mechanism of pairing. Because knowledge about DNA at various levels would be key to helping students understanding these concepts, two coders worked together to determine which apex of the DNA triangle would apply to each passage. The chromosomal code was used when the text consisted of a description of the physical nature of chromosomes (e.g., length, shape, size, telomeres, centromeres). The molecular code was used when the text described DNA in terms of the base pairs or the sequence of bases that comprise DNA. Finally, the informational code was 
applied when the text described DNA in terms of genetic information (e.g., genes, alleles, hereditary information). More than one category code or no code could be applied to statements. A second coder checked all analyses, and all discrepancies were resolved through discussion.

\section{RESULTS}

\section{Identification of Themes}

Biology Experts Agree That Concepts Related to Ploidy, Homology and Mechanism of Homologous Pairing Are Important for Understanding Meiosis. Literature about student difficulties with meiosis, classroom observations, and informal discussions with colleagues helped us construct a list of concepts that were important for understanding the process of meiosis. Table 1 shows the list of concepts that the majority of participants deemed core concepts or important to know for meiosis understanding. Through discussion, the research team aligned each statement within one of the following larger concepts: ploidy, homology, or mechanism of homologous pairing.

Students Have Difficulties Explaining the Concepts of Ploidy, Homology, and Homologous Pairing. Based on the feedback from biology experts about concepts that were important to understand the process of meiosis, meiosis assessment questions were created and then revised based on feedback through interviews with biology students $(N=10)$. This assessment was then distributed to students in a cell biology class, a midlevel course that requires General or Introduction to Biology I as a prerequisite and includes meiosis in its syllabus. Students took this assessment before formal instruction on meiosis so that ideas and preconceptions about linked concepts could be captured. From the 12-question assessment we chose to focus our analysis on the eight questions presented in Table 2, as those most closely aligned with the concept statements listed in Table 1 and were questions that could later be evaluated with the DNA triangle model.

The research team created a rubric articulating the knowledge and reasoning needed to correctly answer each question. Analysis of written responses to the meiosis assessment questions revealed that most students cannot provide correct explanations to questions about ploidy, homologous chromosomes, or mechanism (of crossing over or recombination). Typical student responses and the percentage of students answering correctly for assessment questions are described in Table 2. Very few students were able to correctly answer each question.

Common Themes from Interviews with Biology Students. During the course of this project, our research team conducted 27 interviews (17 interviews conducted with individual students and 10 interviews conducted with pairs of students) about students' understanding of the process of meiosis. Rather than present an exhaustive analysis of each interview exchange, we present and discuss emergent themes from students about ploidy, homologous chromosomes, and mechanism of homologous pairing and crossing over (Table 3 ).

TABLE 3. Interviews from biology students and experts reveal differences between how students and biology experts approach meiosis-related topics

\begin{tabular}{|c|c|c|c|c|}
\hline Questions posed & Typical student ideas & DNA $(\mathrm{C} / \mathrm{M} / \mathrm{I})^{\mathrm{a}}$ & Typical expert ideas & DNA $(\mathrm{C} / \mathrm{M} / \mathrm{I})^{\mathrm{a}}$ \\
\hline \multirow[t]{2}{*}{ What does ploidy mean? } & \multirow{2}{*}{$\begin{array}{l}\text { Ploidy is determined by the structure } \\
\text { of chromosomes; replicated, } \\
\text { two-DNA chromosomes are } \\
\text { considered diploid and unrepli- } \\
\text { cated, one-DNA chromosomes, } \\
\text { are considered haploid. }\end{array}$} & \multirow[t]{2}{*}{$\mathrm{C}$} & $\begin{array}{l}\text { A diploid cell has two of each "type" } \\
\text { of chromosome, one maternal } \\
\text { and one paternal. }\end{array}$ & $\mathrm{C}$ \\
\hline & & & $\begin{array}{l}\text { Ploidy is defined by the number of } \\
\text { unique sets of information in a } \\
\text { cell. }\end{array}$ & I \\
\hline \multirow[t]{2}{*}{$\begin{array}{l}\text { What are homologous } \\
\text { chromosomes? }\end{array}$} & $\begin{array}{l}\text { Homologous chromosomes have the } \\
\text { same size and shape. }\end{array}$ & $\mathrm{C}$ & $\begin{array}{l}\text { Homologous chromosomes are nearly } \\
\text { identical at the sequence level. } \\
\text { Alleles of the same gene may only } \\
\text { differ by a single base. }\end{array}$ & M \\
\hline & $\begin{array}{l}\text { Homologous chromosomes share the } \\
\text { same genetic information (same } \\
\text { genes or alleles). }\end{array}$ & I & $\begin{array}{l}\text { Homologous chromosomes contain } \\
\text { the same genes in the same order } \\
\text { but often contain different alleles. }\end{array}$ & I \\
\hline \multirow[t]{2}{*}{$\begin{array}{l}\text { What determines homologous } \\
\text { pairing? }\end{array}$} & \multirow{2}{*}{$\begin{array}{l}\text { Little knowledge about how or why } \\
\text { homologous chromosomes pair is } \\
\text { evident. }\end{array}$} & \multirow[t]{2}{*}{ - } & $\begin{array}{l}\text { Homology at the DNA sequence level } \\
\text { allows chromosomes to interact. }\end{array}$ & M \\
\hline & & & $\begin{array}{l}\text { Homologous pairing is essential for } \\
\text { proper segregation. }\end{array}$ & I \\
\hline \multirow[t]{2}{*}{ What is crossing over? } & $\begin{array}{l}\text { Crossing over involves segments or } \\
\text { chunks of sister chromatids } \\
\text { exchanging places. }\end{array}$ & $\mathrm{C}$ & $\begin{array}{l}\text { Crossing over occurs when comple- } \\
\text { mentary sequences interact and } \\
\text { form a physical connection } \\
\text { between chromosomes. }\end{array}$ & M \\
\hline & $\begin{array}{l}\text { It is important for creating "genetic } \\
\text { diversity" so "evolution can } \\
\text { happen." }\end{array}$ & I & $\begin{array}{l}\text { It is a way for homologous chromo- } \\
\text { somes to swap information-cre- } \\
\text { ate new combinations of } \\
\text { alleles-so every gamete is } \\
\text { genetically different. }\end{array}$ & I \\
\hline
\end{tabular}

${ }^{a}$ The corner of the DNA triangle referenced in the answer: C, chromosomal; M, molecular; I, informational. 
Ploidy, a concept important to meiosis, is a characteristic of a cell, not of a chromosome, but we have repeatedly heard students anchor their explanations of ploidy on chromosome appearance or DNA content rather than information content. For many students, any cell containing replicated, two-DNA chromosomes must be considered diploid (because there are two visible chromatids and "di" signals two of something), while those containing unreplicated, one-DNA chromosomes are haploid (because they contain "half the DNA" of a diploid cell). For example, students routinely describe cells as being diploid after meiosis I, even though the reductive division has already taken place. Similarly, experts know that the process of DNA replication changes neither ploidy nor chromosome number of a cell, but students typically believe that it does. For example, the majority of students believe that chromosome number doubles after DNA replication, and that the process takes a cell from haploid to diploid ( $n$ to $2 n$ ) or diploid to tetraploid ( $2 n$ to $4 n)$.

When students are asked to explain what homologous chromosomes are and/or provide a definition of what makes them "homologous," the vast majority say that homologous chromosomes have the same size and/or shape: "I know they are usually similar in length," "Size would indicate they are the same." While this type of statement about homologous chromosomes is not incorrect, similar appearance is an effect of homology rather than an explanation of homology. The underlying DNA sequence homology is what results in homologous pairs being the same size and shape-a fact that students are almost never able to articulate. In addition to describing the superficial chromosomal-level characteristics of homologous chromosomes, students will frequently describe homologous chromosomes as sharing the same genetic information or having the same genes or alleles. While this statement is not incorrect either, it is difficult to know what students mean by a vague response like "Genetic make-up. I don't know, the genes.” The literature suggests typical students struggle with concepts related to gene structure and expression and have difficulty understanding the relationships among genes, alleles, and phenotype (Reinagel and Speth, 2016). Genes are segments of DNA and alleles are different versions of genes that usually have nearly identical sequences. Students rarely articulate what they mean by "genes" and "alleles" when they describe homologous chromosomes. In the past, we have documented the vague language students use when describing concepts related to genetic information (Newman et al., 2016), which leaves us to question what students mean when describing the genetic information contained within a pair of homologous chromosomes.

The presence of nearly identical DNA sequence drives the important mechanism of homologous pairing, or "crossing over" during meiosis. In previous work, we reported that students do not transfer their knowledge about DNA when thinking about topics related to chromosome movement and behavior (Newman et al., 2012). We find a similar theme here. Typical biology students have little knowledge of any underlying mechanism and do not use molecular-level knowledge to help themselves understand how homologous chromosomes would pair during meiosis. Many students answer with an "I don't know" or offer vague ideas about "attractions" between chromosomes. While mechanisms are complex and a host of proteins help facilitate this process, homologous chromosomes pair based on DNA sequence complementarity on nearly identical regions. An example of an expert explanation is, "The reason that they are able to pair up is that they have sequences that are either identical or very close in terms of the order so that they can pair up."

In the excerpt below, we show an example of a student who appears to have knowledge about the related molecular mechanism of DNA repair and can even describe "strands of DNA" in terms of homologous recombination/crossing over. However, despite the student being capable of answering the question correctly, s/he decides that knowledge about a molecular process doesn't apply to meiosis:

Interviewer: OK, and how does crossing over happen?

Student 1: The homologous chromosomes mix their DNA?

Student 2: We talked about it in Molecular [class]. Like you have the chromosomes and the DNA strand and the other DNA strand, and they group up, and then it gets-oh, that's DNA repair. Never mind.

Crossing over (recombination) occurs at the molecular level of the DNA strands, but students do not include a description of the molecular interactions in their explanations; students simply describe pieces of chromatids exchanging places. Most students we have worked with describe crossing over, for example,

You got the two chromosomes, and here is one part of one and one part of the other. They break off. So you got this little piece and this piece. And it basically just goes over to the next one like that.

Students often articulate that crossing over is important for genetic diversity and state that crossing over occurs "so evolution can happen," but this is never followed up with an explanation of what that actually means. Note that this is another example of suggesting an effect of a process as an explanation for it-not incorrect, but not accurate either.

\section{Compare/Contrast Student and Expert Ideas}

Common Themes from Interviews with Biology Experts. The research team also conducted six interviews with biology experts (defined as college/university faculty with a $\mathrm{PhD}$ in biology or a related field) about how they thought about meiosis. Rather than present an exhaustive analysis of each interview exchange, we present and discuss how the ideas of experts differ from students in the context of ploidy, homologous chromosomes, and mechanism of homologous pairing and crossing over (Table 3).

Experts are very clear about what makes homologous chromosomes homologous. They focus on the molecular level of DNA in their explanations of homologous chromosomes such as

Homology is where the sequence matches up very, very closely. So if we look at any given chromosome pair, the one from mom and one from the dad, and we compare sequences at every single space, we would find that $99 \%$ are identical between the two.

Experts are able to describe in more detail how meiosis allows homologous chromosomes to exchange genetic information and create new combinations of alleles, which is a source 
of variation for selection to act on. Thus, although students may touch on the concept of genetic information, expert explanations are deeper. Overall, we found that experts and novices focus on different aspects of DNA when explaining ploidy, homology, and mechanism of homologous pairing.

Analysis of Survey Responses by Biology Experts about the Concepts of Homology, Ploidy, and Homologous Pairing. Written responses provided by biology experts $(n=50)$ to the questions posed in the online survey 2 were analyzed. Our firstpass analysis revealed that experts described the concepts of homology and mechanism of homologous pairing very differently than students do. We found that $46 \%$ of experts provided ideas about DNA sequence similarity/complementarity in their reasoning about how homologous chromosomes pair during meiosis. We also found that $44 \%$ of experts described the nearly identical nature of the DNA sequence, and $80 \%$ described the nearly identical nature of the genetic information found in two homologous chromosomes in response to the prompt about what homology means.

Comparison of Findings with Textbook Sources. According to the College Board, the average undergraduate student spends $\$ 1298$ per year on textbooks and other supplies (College Board, 2017). While it is not possible to calculate the exact number of college faculty and undergraduate students who rely on biology textbooks for course material, we assume that the majority of students are assigned textbook readings and that instructors, at least loosely, follow the information presented within the text. It made sense, then, to investigate what ideas textbook authors presented to students. Our results (Figure 3) demonstrate that several concepts, agreed upon by experts as being important for meiosis, were largely absent from the majority of textbooks analyzed. For example, none of the textbooks articulated that maternal and paternal chromosomes of the same kind pair together during meiosis. Out of the statements describing the mechanism of homologous pairing, only one introductory textbook included one of the concept statements. The middle/upper-level textbooks were better, but none of the books had complete coverage of the concept statements relating to the mechanism of homologous pairing. We also noted that only two introductory textbooks explicitly stated that a cell becomes haploid after the first meiotic division.

\section{Development of an Explanatory Framework}

Up until this point in our work, we had been focusing on the concepts of ploidy, homology, and mechanism of homologous pairing. Now we began to think about how we conceptualize DNA when describing these concepts. From our analyses, it was obvious that experts brought in their molecular-level knowledge of DNA and incorporated this knowledge with knowledge about chromosome structure and genetic information. We also realized/found a tension-none of the levels was sufficient to explain any of the concepts; all were necessary to understand meiosis as a whole. This connectedness of three DNA levels led us to develop the DNA triangle (Figure 2A), whose corners represent the different levels of DNA (chromosomal, molecular, and informational). We then realized that the concepts we had been studying about meiosis could be mapped to the sides of the triangle (Figure 2B).

\section{Applying the Framework}

Student Themes. As discussed above, first-pass analysis of data revealed that biology experts approached the subject of meiosis differently from novices. A second-pass analysis applied the DNA triangle to themes identified from interviews with experts and novices. As shown in Table 3, students rarely address the molecular level (M) of DNA in their explanations,

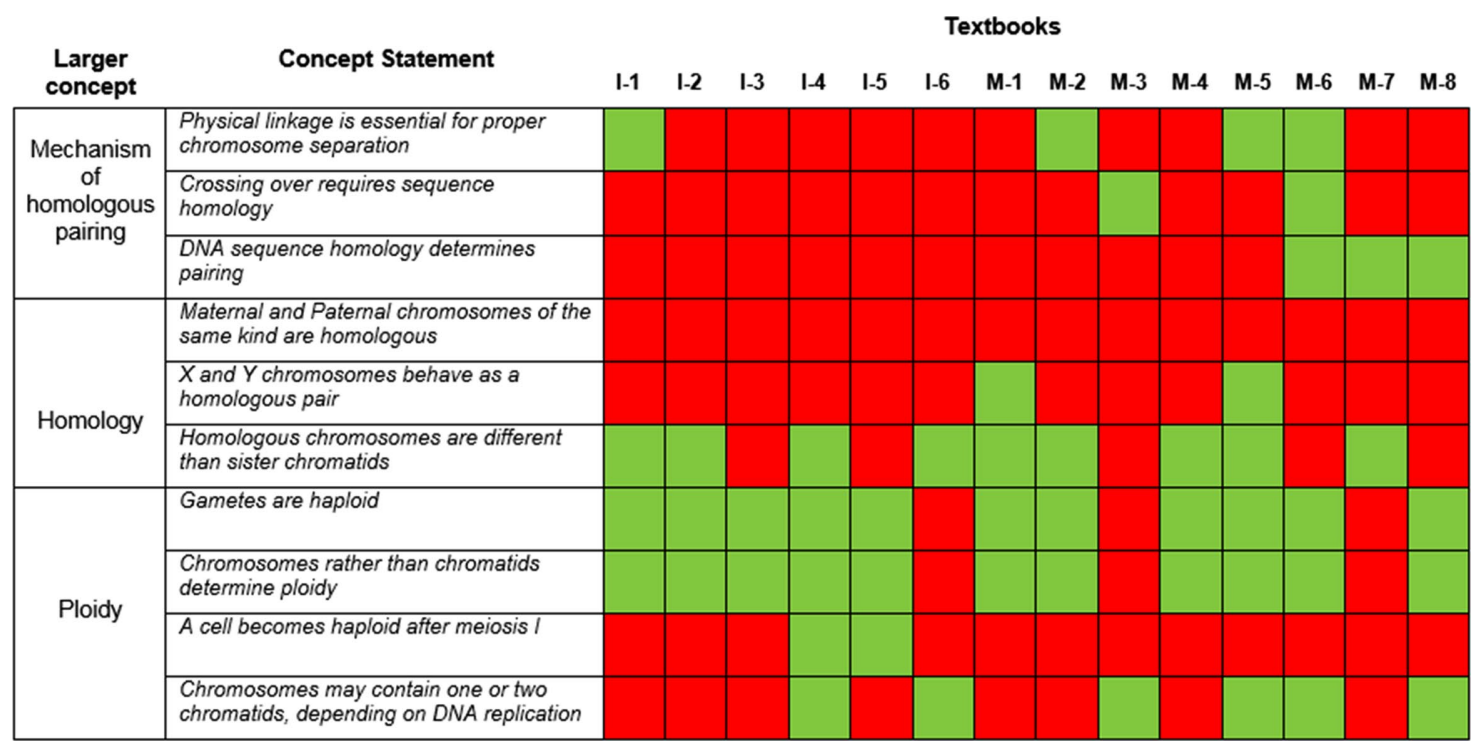

FIGURE 3. Not all important concepts about meiosis are found in textbooks. Six introductory-level biology textbooks (I-1 through I-6) and eight middle/upper-level textbooks (M-1 through $\mathrm{M}-8$ ) were analyzed for the presence of statements about homologous pairing, homology, and ploidy. Textbooks are identified in Supplemental Table 1. Green indicates the presence of the concept, while red indicates its absence. 
TABLE 4. Application of the DNA triangle to passages from introductory and middle/upper-level biology textbook passages

\begin{tabular}{|c|c|c|c|}
\hline & Molecular & Chromosomal & Informational \\
\hline Ploidy & $\begin{array}{l}\text { Not found in any of the textbooks } \\
\text { analyzed }\end{array}$ & $\begin{array}{l}\text { The number of chromosome sets is } \\
\text { termed the cell's ploidy. Diploid } \\
\text { cells or species are designated } \\
2 n \text {, because two chromosomes } \\
\text { of each type are present } \\
\text { (Freeman et al., 2016). }\end{array}$ & $\begin{array}{l}\text { Organisms can carry one or more copies of } \\
\text { the individual genes. For example, } \\
\text { yeast can survive indefinitely as a } \\
\text { haploid organism, carrying a single } \\
\text { copy of its genomes (Craig et al., } \\
\text { 2010). }\end{array}$ \\
\hline Homology & $\begin{array}{l}\text { At the molecular level how, similar are } \\
\text { homologous chromosomes? The } \\
\text { answer is that the sequence of bases of } \\
\text { one homolog usually differs by less } \\
\text { than } 1 \% \text { compared with the sequence } \\
\text { of the other homolog (Brooker, 2012). }\end{array}$ & $\begin{array}{l}\text { The two chromosomes of a pair } \\
\text { have the same length, } \\
\text { centromere position, and } \\
\text { staining pattern: These are } \\
\text { called homologous chromo- } \\
\text { somes (Reece et al., 2013). }\end{array}$ & $\begin{array}{l}\text { For example, if a gene for eye color is } \\
\text { situated at a particular locus on a } \\
\text { certain chromosome, then the homolog } \\
\text { of that chromosome will also have a } \\
\text { version of the same gene specifying eye } \\
\text { color at the equivalent locus (Reece } \\
\text { et al., 2013). }\end{array}$ \\
\hline $\begin{array}{l}\text { Mechanism of } \\
\text { homologous } \\
\text { pairing }\end{array}$ & $\begin{array}{l}\text { In many organisms, the initial associa- } \\
\text { tion-the process of pairing-seems to } \\
\text { be mediated by an interaction between } \\
\text { matching maternal and paternal DNA } \\
\text { sequences at numerous sites that are } \\
\text { widely dispersed along the chromo- } \\
\text { somes (Alberts et al., 2009). }\end{array}$ & $\begin{array}{l}\text { Each pair of duplicated homologs } \\
\text { is now held together by at least } \\
\text { one chiasma... the connection } \\
\text { that corresponds to a crossover } \\
\text { between two non-sister } \\
\text { chromatids. (Alberts et al., } \\
\text { 2009). }\end{array}$ & $\begin{array}{l}\text { Homologous chromosomes continue to } \\
\text { condense and undergo synapsis } \\
\text { (gene-for-gene pairing) (Morris et al., } \\
\text { 2015). }\end{array}$ \\
\hline
\end{tabular}

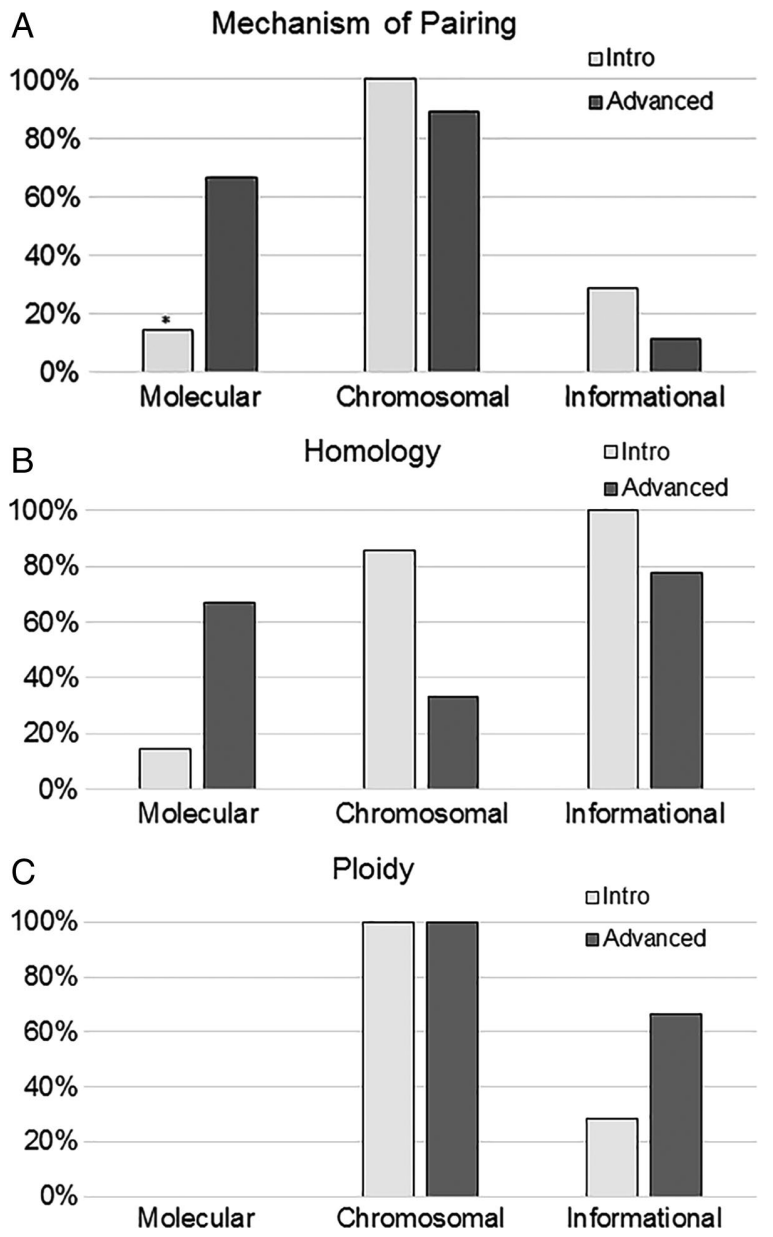

FIGURE 4. Comparison of introductory and middle/upper-level textbooks. (A) Mechanism of homologous pairing, (B) homology, and (C) ploidy. Textbooks used here are identified in Supplemental Table 2. *The one introductory textbook that mentioned DNA focusing instead mainly on the chromosomal level (C) and sometimes on the informational level (I). In contrast, experts use all three levels and, most strikingly, incorporate the molecular level (M) for discussions about homology and homologous pairing/crossing over.

Textbook Content. Our first-pass analysis of 14 college-level biology books revealed that concepts important for understanding the process of meiosis were missing from a large number of textbooks. We decided to use a new set of textbooks and look more explicitly at how homology, ploidy, and homologous pairing were presented to students. We hypothesized that students' inability to correctly reason about meiosis-related concepts at the molecular level may be due, in part, to how these concepts were presented in their textbooks. Textbooks were coded for how authors presented the concepts of homology, ploidy, and mechanism of homologous pairing in terms of the DNA triangle. Table 4 illustrates examples of how textbook passages were coded. Our data revealed that introductory textbooks approach these topics differently from middle/upper-level textbooks and differently from how experts described meiosis during interviews. Most striking was the absence of nearly any mention of the molecular scale of DNA in introductory chapters on meiosis. This lack was most apparent when it came to explaining the concepts of homology and mechanism of homologous pairing (Figure 4, A and B). The introductory books largely presented concepts about homology and identification of homologous chromosomes in terms of chromosomal appearance (C) and genetic information (I), while only one of seven textbooks described the molecular aspect of the DNA (M) at all. Introductory texts also presented the mechanism of homologous pairing

sequence similarity of homologous chromosomes did so only in the context of $X$ and $Y$ pairing, which could have been construed by a reader as an exception rather than the rule of what makes chromosomes homologous. 
TABLE 5. The DNA triangle applied to expert explanations $(N=50)$ of ploidy, homologous chromosomes, and mechanism of homologous pairing

\begin{tabular}{lccc}
\hline & \multicolumn{3}{c}{ DNA triangle } \\
\cline { 2 - 4 } Concept & Molecular & Chromosomal & Informational \\
\hline Ploidy & $2.0 \%$ & $86.0 \%$ & $22.0 \%$ \\
Homologous & $32.0 \%$ & $24.0 \%$ & $80.0 \%$ \\
$\quad$ chromosomes & & & \\
$\begin{array}{c}\text { Mechanism of } \\
\quad \text { homologous } \\
\text { pairing }\end{array}$ & $59.0 \%$ & $33.3 \%$ & $20.5 \%$ \\
\hline
\end{tabular}

at the chromosomal (C) level, with only one of seven books making an attempt to bring in complementary base-pairing of homologous pairs (M). On the other hand, many middle/upperlevel textbooks used explanations that sounded much more similar to our experts' statements-homology fundamentally means near identity at the DNA sequence level, and this similarity is the basis for homologous pairing at a molecular level, which allows for the precision of segregation during meiosis I. The informational aspect of DNA was also much more commonly used to explain ploidy in more advanced books (Figure 4C).

Expert Themes. A second-pass analysis of the written survey responses from experts revealed similar trends (Table 5). For each concept, we note that the top two DNA triangle apexes referenced by experts are in agreement with how middle/upperlevel textbooks describe the concepts of ploidy, homologous chromosomes, and mechanism of homologous pairing. Experts describe ploidy mainly at the chromosomal and informational levels. Homologous chromosomes are described mainly on the basis of molecular and informational levels, and mechanism of homologous pairing is described mainly at the molecular and chromosomal levels.

\section{DISCUSSION}

We have used the foundational ideas of Johnstone's triangle to leverage our data on student understanding of meiosis and present a new framework that can be applied to teaching and learning meiosis: the DNA triangle (Figure 2). We emphasize that our model is analogous to Johnstone's triangle framework, not just an application of Johnstone's framework to biology. Johnstone, in fact, did broadly apply his framework to biology, describing a macro level (plants and animals), a micro level (cells), and a biochemical level (DNA) (Johnstone, 1991). This strategy, however, has been criticized because of the nested structure of biological organization: biochemicals are nested within cells, which are nested within tissues, which are nested within organs, which are nested within organisms, which are nested within populations, which are nested within ecosystems (Tsui and Treagust, 2013). Tsui and Treagust suggested a cube model for biology, wherein levels of organization intersect different kinds of symbolism and knowledge domains. Our framework, on the other hand, centers explicitly on DNA, without attempting to cover all of biology. Like Johnstone's model, our DNA triangle represents the three different scales at which DNA can be considered. The chromosomal level is anal- ogous to Johnstone's macroscopic level; this represents a level of DNA that is visible under the microscope. Because DNA is packaged into dynamic structures, the chromosomal level of DNA is crucial to consider during complex biological processes. Our molecular level is akin to Johnstone's submicroscopic level and represents a physical entity that is not visible. DNA is a macromolecule that is composed of nucleotide building blocks, with the sequence of the nucleotides being crucial for molecular interactions. Because it is the sequence of nucleotide bases that allows DNA to be a functional molecule, the molecular level of DNA is crucial to consider. DNA also encodes the genetic information passed from parent to daughter cell, directing the inheritance of genetic traits. Unlike the other two levels, this information cannot be touched or even visualized directly, but it is nonetheless an integral component of the concept of DNA. Our third level, therefore, is informational. The informational level is connected to the other two levels in a way that the symbolic level did not connect to macroscopic or submicroscopic in Johnstone's framework. In the context of Johnstone's triangle, Taber (2013, p. 158) pointed out that there has been "confusion over what is meant by a symbolic 'level'-how it fits in an ontology with 'macroscopic' and 'submicroscopic,' and how it relates to notions of there being three different representational levels." Johnstone described the symbolic level as the math, equations and chemical formulae that can be used to describe or represent what is happening at the macroscopic and submicroscopic levels.

So where, then, does the symbolic level fit with the DNA triangle? We do not envision it as equivalent to (on the same plane as) the other three levels. Perhaps the symbolic can be integrated throughout all levels of the DNA triangle. Another way to envision our DNA framework is as a tetrahedron with the symbolic level connected to three other corners. In other words, each level of DNA can be represented symbolically: chromosomes (C) can be represented by sticks, lines, and ovals; the molecular sequence of DNA (M) can be represented by As, Ts, Cs, and Gs or chemical structures; and the informational level (I) can be represented by conventions for alleles such as "B/b," pictures representing phenotypes, or even Punnett squares; all representations of the informational aspect of DNA.

We suggest the DNA triangle can be applied to teaching and learning important concepts about meiosis. Our model (Figure 2) is supported by evidence collected from biology experts and middle/upper-level biology textbooks. This model not only offers instructors a tool for framing instruction and in-class activities, it also acknowledges the centrality of all aspects of the DNA triangle to the key aspects of the process of meiosis (homology, ploidy, and mechanism). Ploidy describes the amount of unique genetic information that is contained within a cell. Because genetic information is packaged within chromosomes, this concept relies on thinking about DNA at both the chromosomal and informational levels. Therefore, ploidy bridges the chromosomal and informational apexes on the DNA triangle. Because of their descent from a common evolutionary ancestor, homologous chromosomes share a nearly identical sequence of DNA bases and, of course, share the same basic genetic information (although potentially different alleles). The concept of homologous chromosomes, therefore, sits on the side that connects the molecular and informational corners of the DNA triangle. The mechanism of homologous pairing 
involves the physical interaction of complementary base sequences between single strands of DNA from each homologue, and the mechanism of homologous pairing connects knowledge of DNA at the chromosomal and molecular levels.

Application of the DNA triangle to teaching and learning meiosis reveals a major issue in how concepts related to meiosis are presented in introductory biology textbooks. Note that the mechanism of homologous pairing is primarily described at the molecular and chromosomal levels in the middle/upper-level textbooks, which is in agreement with our framework, but this topic is mainly described at the chromosomal level with a little of the informational level in the introductory texts (Figure 4A). Thus, the advanced books describe the mechanism at the appropriate levels of DNA, whereas the introductory books are either focused on a single apex or on the wrong side of the triangle. Similarly, homology/homologous chromosomes are described primarily at the informational and molecular levels in middle/ upper-level textbooks, but at the chromosomal and informational levels in introductory books. Again, the focus in the advanced books is in accordance with our model, but the introductory books focus too heavily on chromosomal aspects of DNA when describing homologous chromosomes. It is little wonder that most students describe homologous chromosomes as having the same size and shape but do not realize that homologous chromosomes have nearly the same underlying DNA sequence. We suggest that introductory textbooks are not priming students to consider the molecular level of DNA when describing homologous chromosomes. The introductory books do best with the concept of ploidy, perhaps because this concept does not directly involve the molecular level, but they still often fail to include both necessary apexes and tend to rely on only chromosomal explanations. We suggest that this leads to a surface rather than a deep understanding of the concept. Part of this issue may be due to the fact that instruction on the topics of chromosomes, meiosis, and heredity is part of high school, possibly even middle school, curricula. It might be reasonable to expect that younger students do not have a solid foundation of molecular knowledge, so topics are first presented at the chromosomal level of DNA. Unfortunately, the majority of college-level biology textbooks we analyzed continue to present topics of homology and mechanism of homologous pairing at the chromosomal and informational levels, not at the molecular level. While biology experts (i.e., academic faculty) certainly understand homology and mechanism of homologous pairing at the molecular level, if they are not explicit during instruction, students may continue to think about meiosis on a nonmolecular level.

This tension between levels has been illustrated in other disciplines, such as chemistry. In previous work, Tasker and Dalton (2006) pointed out that much of chemistry instruction occurs at the macroscopic level: students spend much time interpreting observable changes in matter in the laboratory. These macroscopic observations are then represented at the symbolic level using chemical notation and/or equations and graphs, which is challenging for many students. Difficulties in learning chemistry concepts, though, are often rooted in the inability of novices to visualize structures and processes at the molecular/submicroscopic scale. We argue this is analogous to our findings concerning meiosis instruction: the molecular level is largely absent from instruction, particularly at the introductory level. One of the out- puts of the realization in chemistry has been the VisChem project; software was created to help students develop better mental models of chemical phenomena at the molecular level using carefully designed computer animations (Tasker and Dalton, 2006). The intention of the VisChem tools is to explicitly communicate molecular-level features of chemical phenomena to help chemistry learners link the macroscopic to the symbolic levels.

\section{Implications for Teaching}

We suggest interventions are needed to explicitly bring the molecular-level structure of DNA into meiosis-related topics at the introductory biology levels. To address the lack of connection between the molecular level of DNA (i.e., sequence of bases) with concepts of homology and mechanism of homologous pairing, we have created an interactive lesson in which students become chromosomes by holding long strips of paper on which a DNA sequence is printed (Newman and Wright, 2017). Through this activity, students are encouraged to deepen their understanding of homology by comparing base sequences of all six chromosomes to identify homologous chromosome pairs. Students also uncover the mechanism of homologous pairing by physically aligning and crossing over complementary bases on sister chromatids using the printed DNA sequence as a visual and physical aid. In our experience, students who participated in this activity demonstrated surprise when they learned about the mechanism of homologous paring and also showed learning gains on selected Meiosis Concept Inventory questions (Kalas et al., 2013) that relate to chromosome structure, homology, and mechanism, improving from an average of $26 \%$ to $42 \%$ correct $(n=20, p=0.003)$. Students also demonstrated correct reasoning when answering application questions about recombination, such as describing how nonmeiotic recombination events might result in chromosomal translocations.

While we have not rigorously tested how the DNA triangle could be integrated into classroom instruction, we envision the framework as a useful tool for instructors and students. Instructors, for example, could use the DNA triangle to evaluate in-class activities and models about meiosis to make sure that appropriate attention is paid to the molecular structure of DNA during all parts of the lesson. Instructors could design formative or summative assessments based on the framework, for example, asking students to explain a particular phenomenon by using and integrating their knowledge of all three levels of DNA. Students might even find the framework to be a useful learning tool; perhaps it could be incorporated into class materials and help remind students where they are "in the triangle" as they discuss and reason through different topics.

We also point out that instructional materials of meiosis-related concepts at the molecular level of DNA need not be overly complex or technical, especially for students at the introductory levels. Here, we present an excerpt from a textbook that explains homologous chromosomes on the informational and molecular levels of DNA and then acknowledges that homologous chromosomes would, therefore, have similarities at the chromosomal level:

The two members of each chromosome pair are called homologous chromosomes. Two homologous chromosomes generally carry the same genes in the same order, although for any given gene, the two versions differ slightly in base sequence. Not 
surprisingly, homologous chromosomes usually look alike when viewed with a microscope. (Hardin and Bertoni, 2015, p. 747)

We suggest the DNA triangle model could also be applied to other complex biology topics that rely on knowledge of DNA at varying levels. Regulation of gene expression, for example, is a topic to which the DNA triangle can be applied. The structure of chromatin (chromosomal level) impacts the accessibility of the DNA to transcriptional machinery. The base sequence of the DNA (molecular level) at regulatory regions allows binding (or not) of enzymes and regulatory protein factors that regulate synthesis of mRNA. Finally, gene expression itself is the manifestation of hereditary material and thus can also be considered at the informational level. We suggest the DNA triangle is a useful framework for creating classroom activities and assessment questions on complex topics in biology that require knowledge of multiple levels of DNA for deep understanding. This paper models how the DNA triangle can be applied to meiosis and suggests that interventions that help students connect and apply the appropriate levels of DNA may improve learning on these challenging topics. We present this framework to the biology education research community for consideration and further testing in the context of learning meiosis and other complex biological processes.

\section{ACKNOWLEDGMENTS}

We thank undergraduate students Eric Zajicek and Kayla DeOca for assistance with data collection and analysis. We also appreciate many conversations with members of the RIT Science and Mathematics Research Collaborative (SMERC) that helped clarify our thinking.

\section{REFERENCES}

Alberts, B., Bray, D., Hopkin, K., Johnson, A. D., Johnson, A., Lewis, J., .. Walter, P. (2009). Essential cell biology (pp. 657-658). Garland Science.

American Association for the Advancement of Science. (2011). Vision and change in undergraduate biology education: A call to action Washington, DC.

Bédard, J., \& Chi, M. T. H. (1992). Expertise. Current Directions in Psychological Science, 1, 135-139.

Brooker, R. (2012). Concepts of genetics, 21. McGraw-Hill Education.

Chi, M. T. H. (2006). Two approaches to the study of experts' characteristics. In Ericsson, K. A., Charness, N., Feltovich, P. J., \& Hoffman, R. R. (Eds.), The Cambridge handbook of expertise and expert performance (pp. 21-30). Cambridge: Cambridge University Press.

College Board. (2017). Understanding College Costs. BigFuture. Retrieved April 26, 2017, https://bigfuture.collegeboard.org/pay-for-college/college - costs/quick-guide-college-costs

Craig, N., Cohen-Fix, O., Green, R., Greider, C., Storz, G., \& Wolberger, C. (2010). Molecular biology: Principles of genome function, 18. Oxford Oxford University Press

Dikmenli, M. (2010). Misconceptions of cell division held by student teachers in biology: A drawing analysis. Science Research Essay, 5, 235-247.

Freeman, S., Quillin, K., Allison, L., Black, M., Taylor, E., Podgorski, G., \& Carmichael, J. (2016). Biological science. Boston: Pearson, 273.

Freidenreich, H. B., Duncan, R. G., \& Shea, N. (2011). Exploring middle school students' understanding of three conceptual models in genetics. International Journal of Science Education, 33, 2323-2349.

Galloway, K. R., \& Bretz, S. L. (2015). Measuring meaningful learning in the undergraduate chemistry laboratory: A national, cross-sectional study. Journal of Chemical Education, 92, 2006-2018.
Glaser, B. G., \& Strauss, A. L. (1967). The discovery of grounded theory: Strategies for qualitative research. New York: Routledge.

Hardin, J., \& Bertoni, G. P. (2015). Becker's world of the cell, books a la carte (9th) edition, Boston: Pearson

Hmelo-Silver, C. E., Marathe, S., \& Liu, L. (2007). Fish swim, rocks sit, and lungs breathe: Expert-novice understanding of complex systems. Journal of the Learning Sciences, 16, 307-331.

Johnson, B., \& Christensen, L. (2008). Data analysis in qualitative and mixed research. In Educational research: Quantitative, qualitative, and mixed approaches (pp. 529-556). Thousand Oaks, CA: Sage.

Johnstone, A. H. (1991). Why is science difficult to learn? Things are seldom what they seem. Journal of Computer Assisted Learning, 7, 75-83.

Johnstone, A. H. (2000). Teaching of chemistry-Logical or psychological? Chemistry Education Research and Practice in Europe, 1, 9-15.

Johnstone, A. H., \& Mahmoud, N. A. (1980). Isolating topics of high perceived difficulty in school biology. Journal of Biological Education, $14,163-166$

Kalas, P., O'Neill, A., Pollack, C., \& Birol, G. (2013). Development of a Meiosis Concept Inventory. CBE-Life Sciences Education, 12, 655-664.

Kilic, D., Taber, K. S., \& Winterbottom, M. (2016). A cross-national study of students; understanding of genetics concepts: Implications from similarities and differences in England and Turkey. Education Research International, 2016, e6539626.

Kindfield, A. C. H. (1991). Confusing chromosome number and structure A common student error. Journal of Biological Education, 25, 193200

Kindfield, A. C. H. (1994). Understanding a basic biological process: Expert and novice models of meiosis. Science Education, 78, 255-283.

Komives, S. R., Longerbeam, S. D., Owen, J. E., Mainella, F. C., \& Osteen, L. (2006). A leadership identity development model: Applications from a grounded theory. Journal of College Student Development, 47, 401418

Kozma, R., \& Russell, J. (1997). Multimedia and understanding: Expert and novice responses to different representations of chemical phenomena. Journal of Research in Science Teaching, 34, 949-968.

Levrini, O., Fantini, P., Tasquier, G., Pecori, B., \& Levin, M. (2015). Defining and operationalizing appropriation for science learning. Journal of the Learning Sciences, 24, 93-136.

Marbach-Ad, G. (2001). Attempting to break the code in student comprehension of genetic concepts. Journal of Biological Education, 35, 183 189.

Martin, P. Y., \& Turner, B. A. (1986). Grounded theory and organizational research. Journal of Applied Behavioral Science, 22, 141-157.

Morris, J., Hartl, D., Knoll, A., Lue, R., Michael, M., Berry, A., ... Holbrook, N. M. (2015). Biology: How life works (p. 226). W. H. Freeman.

Newell, A., \& Simon, H. A. (1972). Human problem solving, Englewood Cliffs NJ: Prentice-Hall.

Newman, D. L., Catavero, C., \& Wright, L. K. (2012). Students fail to transfer knowledge of chromosome structure to topics pertaining to cell division. CBE-Life Science Education, 11, 425-436

Newman, D. L., Snyder, C. W., Fisk, J. N., \& Wright, L. K. (2016). Development of the central dogma concept inventory $(C D C I)$ assessment tool. $C B E-$ Life Science Education, 15, ar9.

Newman, D. L., \& Wright, L. K. (2017). Meiosis: A play in three acts, starring DNA sequence. Course Source. https://doi.org/10.24918/cs.2017.9

Otero, V. K., \& Harlow, D. B. (2009). Getting started in qualitative physics education research. In Henderson, C., \& Harper, K.A. (Eds.), Getting started in PER (pp. 1-66). College Park, MD: American Association of Physics Teachers.

Powietrzynska, M., Tobin, K., \& Alexakos, K. (2014). Facing the grand challenges through heuristics and mindfulness. Cultural Studies of Science Education, 10, 65-81

Reece, J. B., Urry, L. A., Cain, M. L., Wasserman, S. A., Minorsky, P. V., \& Jackson, R. B. (2013). Campbell biology (p. 254). Boston: Pearson.

Reinagel, A., \& Speth, E. B. (2016). Beyond the central dogma: Model-based learning of how genes determine phenotypes. CBE-Life Science Education, 15, ar4 


\section{K. Wright et al.}

Scherr, R. E. (2007). Modeling student thinking: An example from special relativity. American Journal of Physics, 75, 272-280.

Shaw, K. R. M., Van Horne, K., Zhang, H., \& Boughman, J. (2008). Essay contest reveals misconceptions of high school students in genetics content. Genetics, 178, 1157-1168

Smith, M. K., \& Knight, J. K. (2012). Using the Genetics Concept Assessment to document persistent conceptual difficulties in undergraduate genetics courses. Genetics, 191, 21-32

Stewart, J., Hafner, B., \& Dale, M. (1990). Students' alternate views of meiosis. American Biology Teacher, 52, 228-232.

Strauss, A. L., \& Corbin, J. M. (1997). Grounded theory in practice, Thousand Oaks, CA: Sage.

Suddaby, R. (2006). From the editors: What grounded theory is not. Academy of Management Journal, 49, 633-642.
Taber, K. (2013). Revisiting the chemistry triplet: Drawing upon the nature of chemical knowledge and the psychology of learning to inform chemistry education. Chemistry Education Research and Practice, 14, 156168.

Tasker, R., \& Dalton, R. (2006). Research into practice: Visualisation of the molecular world using animations. Chemistry Education Research and Practice, 7, 141-159.

Tsui, C.-Y., \& Treagust, D. F. (2013). Introduction to multiple representations: Their importance in biology and biological education. In Treagust, D. F., \& Tsui, C.-Y. (Eds.), Multiple representations in biological education (pp. 3-18). Springer. DOI:10.1007/978-94-007-4192-8_1

Wright, L. K., \& Newman, D. L. (2011). An interactive modeling lesson increases students' understanding of ploidy during meiosis. Biochemistry and Molecular Biology Education, 39, 344-351. 